\title{
DYNAMICS IN THE LINE STRUCTURE OF THE TROTTER BREED IN BULGARIA
}

\author{
N. Lukanova* \\ National Association of Horse Breeding, Sofia, Bulgaria
}

\begin{abstract}
The dynamics in the development of the linear structure of trotter horses in Bulgaria has been studied. All stallions imported in Bulgaria that have taken part in the breeding process have been included in the study. The analysis outlines clearly three periods in the formation of the linear structure. The first one is based on stallions from the Orlow trotter, the second one are stallions from the Russian trotter and the third one are stallions from the Standardbred. The development of the linear structure during the first two periods is presented in detail in 5 diagrams.
\end{abstract}

Keywords: trotter horses, linear structure

\section{INTRODUCTION}

Horses of the four officially recognized trotter breeds (Standardbred, Orlow, French and Russian Trotter) are among the most common breeds of horses worldwide. In popularity they rank after the Thoroughbred as racehorses. They are being studied due to the increasing number associated with their participation in the racecourse racing buggies. These events are a source of revenue in countries with traditionally developed trotter horse breeding (1).

Studies related to the linear and family structure of the breed have not been made. Linebreeding is the highest form of selection and is was first applied in horse breeding in the 18th century (2). Originally it was used in horses of the Thoroughbred and then applied in the Orlow Trotter (3). Family breeding was first used in mares of the Thoroughbred breed. Mares were classified and arranged in tables to indicate "common ancestor" (4).

In this relation, we set out to explore the dynamics of population development of trotter horses in Bulgaria and their linear structure formed on the basis of imported stallions of various breeds.

*Correspondence to: $N$. Lukanova,National Association of Horsebreeding, 1756 Sofia, Bistrishko shose, str. № 26, e-mail address: nik.nade@abv.bg
The first studies on the genealogy of the Standardbred horse were made by John Hervey and published in the book "The Standardbred" in 1947 (5-6). Modern lines in the breed are six line of Rodney (by Happy Medium), line of Victory Song (by Happy Medium), line of Star`s Pride (by Happy Medium), line of Axworthy (by George Wilkes), line of Mc Kinney (by George Wilkes) and line of Bingen (by Electioneer) by the three sons of the stallion Hambletonian X (7). In creating the Orlow Trotter breed 11 lines were formed, the currently existing lines being 8 - Line of Boltik, Proliv, Veter, Pion, Velyobot, Voin, Barchuk, Otboy, Uspeh, Pilot, Kvadrat (8). In the French Trotter breed the baselines are also six, the currently existing ones being four - Line of Conquérant, line of Normand, line of Phaëton, line of Niger, line of Lavater and line of Hambletonian X (9). The Russian Trotter breed is represented by 12 lines - Line of AloyshaPodarok, Antoniy, Bonapart, Gazavat, Gildeetz, Dodar, Zamorskoe Chudo, Nalim, Trepet, Axworthy, Volomite, Scotland (10).

In our country work with these breeds began in 1894 when the first trotter horses of the Orlow Trotter were imported. Work with them continued until 1924. Considered historically trotter horse breeding in Bulgaria is characterized by repeated import of stallions and mares (11). 


\section{MATERIAL AND METHODS}

As a source of information we used the database of the National Horsebreding Association relating to registration of imported horses in the country and their breeding activities. The study was done in person, using routine zootechnical methods for monitoring and analysis.

Suffixes in the schemes are presented according to ISO 3166, under the agreement of the European Trotting Union and they reflect the place of birth of the horses.

\section{RESULTS AND DISCUSSION}

The first period is from 1954 to 1962, when stallions of the Orlowski Trotter breed were mostly imported; the second one is from 1963 to 1986, when stallions of the Russian Trotter breed were imported and the third one is from 1987 continuing to this date. The third period is characterized by the import of stallions from leading European countries. Most of the stallions
LUKANOVA N.

imported are of the Standardbred and French Trotter breeds.

In the first period two stallions of the Orlow Trotter breed were imported from the USSR. These are the stallions Vororbishek and Perlamutr.

After this period, in 1962, an import of stallions of the Russian Trotter breed followed from the then USSR. As soon as the same year the stallion Labaz of the Russian Trotter breed was imported. He is of the Aloysha-Podarok line, the branch of Podarok, which is currently nonexistent in Russia.

Despite the widespread use of the stallion in Bulgaria, only his son Leopold is a continuation of the line through his sons Laudon the Second and Lagos, and stallion Logan - son of Lagos (Figure 1).

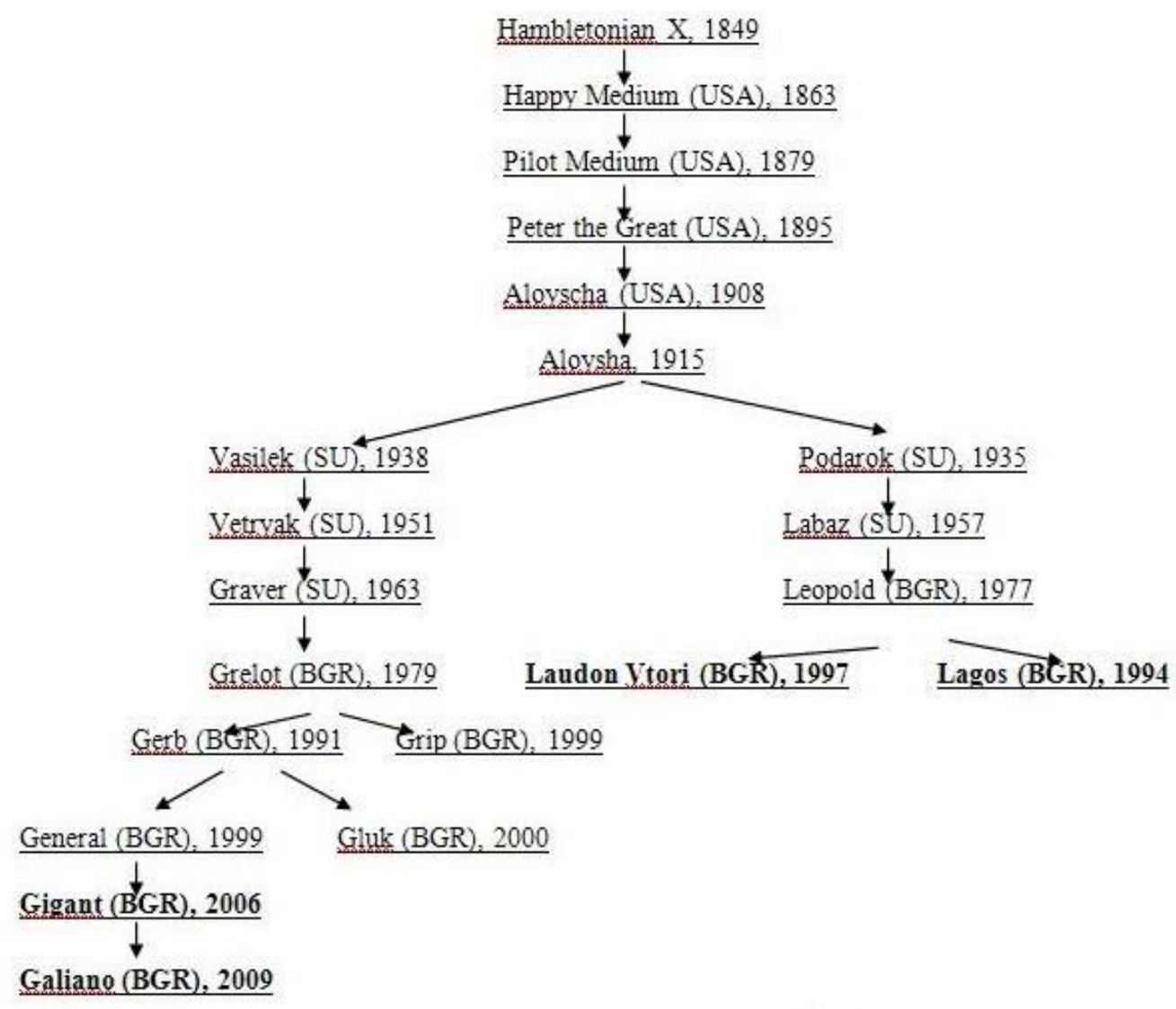

Figure 1. Line of Aloysha-Podarok Branch of PodarokBranch of Vasilek

Again of the same line, but from the other branch of Vasilek in 1972 stallion Graver was imported of the Russian Trotter breed. It is that stallion that left the deepest mark in trotter horse breeding in Bulgaria. Today's representatives are stallion Gigant and his son Galiano. Typical of the representatives of this line is that they move in pace amble and their grey color (Figure 1).

Of the Star`s Pride line, the branch of Apex Hanover in 1980 stallion Unikum of the Russian Trotter horse breed was imported. Nowadays the 
stallion has got three grandsons and one greatgrandson, but unfortunately the line is not widely used in the trotter gorse breeding process in our country (Figure 2). Of the line of Guy Axworthy, the branch from High Noon a representative in Bulgaria is stallion Neptune, also imported in 1980 from the USSR. Stallion Neptune acted as a Pepiniere stallion from 1982 to 1987 in "Khan Asparouh" stud. Nowadays the stallion is represented by his three grandsons Neutilos, Narcis the Second and Numizmat (Figure 3).

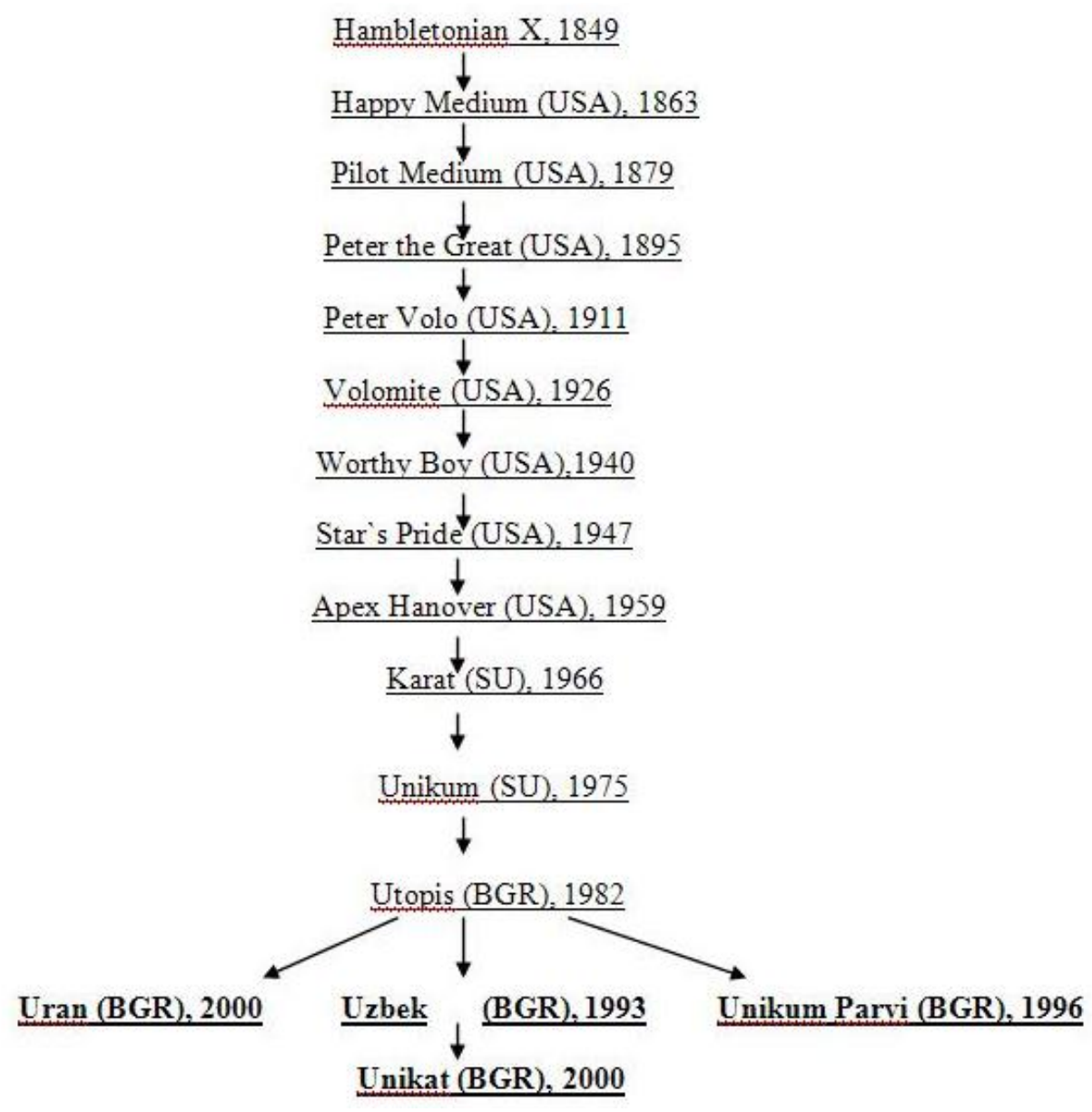

Figure 2. Line of Star`s PrideBranch of Apex Hanover

From the second branch of the same line - of stallion Truax, the representative in Bulgaria is stallion Suhart. His mother Amazon was imported pregnant from stallion Super Hanover from Hungary. Unfortunately stallion Suhart is not competitive to stallions imported from European countries and is less used for breeding (Figure 3).

In 1987 the fifth import of horses from the former USSR was made, which marked the beginning of the third period of trotter horse beeding in our country. Among them is the stallion Izdatel of the Russian Trotter breed of Lowe Hanover line and he is grandson of Star's Pride. The line was widely used in the country until about 2005, but at the moment it is not so popular. Many of the stallions representatives of this line are exported to Turkey, where currently they take part in trials under saddle in pace amble (Interpol, Inun, Inter Milano, Idan and Istanbul II). Stallions Iriney Parvi and Inter Star are the only representatives of the line in Bulgaria (Figure 4).

In 1993 the stallions Negus and Kirasir of the Russian Trotter breed were imported from Russian into Bulgaria. Of the line of stallion Negus no followers were left and it was discontinued.

Of the Scotland line from the Centennial Way branch a representative in our country is stallionKirasir. Unfortunately, only his grandson stallion Kent is currently a successor of the line (Figure 5). 
Hambletonian X,1849

George Wilkes (USA). 1856

William L (USA), 1882

Axtell (USA), 1886

Axworthy (USA), 1892

Guv Axworthy (USA), 1902

High Noon (USA), 1923

Big Noon (SWE), 1936

Tomado (SWE), 1952

Neptun (SU). 1973

Narcis (BGR). 1985

Truax (USA), 1921

Calumet Chuck (USA), 1929

Nibble Hanover (USA), 1936

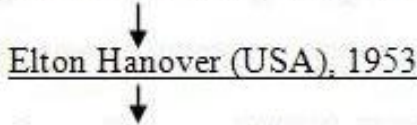

Super Hanover (HUN), 1967
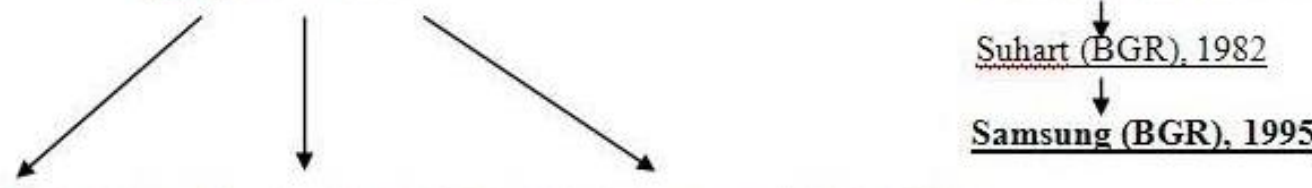

Neutilos (BGR), 1999 Narcis Vtori (BGR), 2005 Numizmat (BGR), 2004

Figure 3. Line of Guy AxworthyBranch of High NoonBranch of Truax

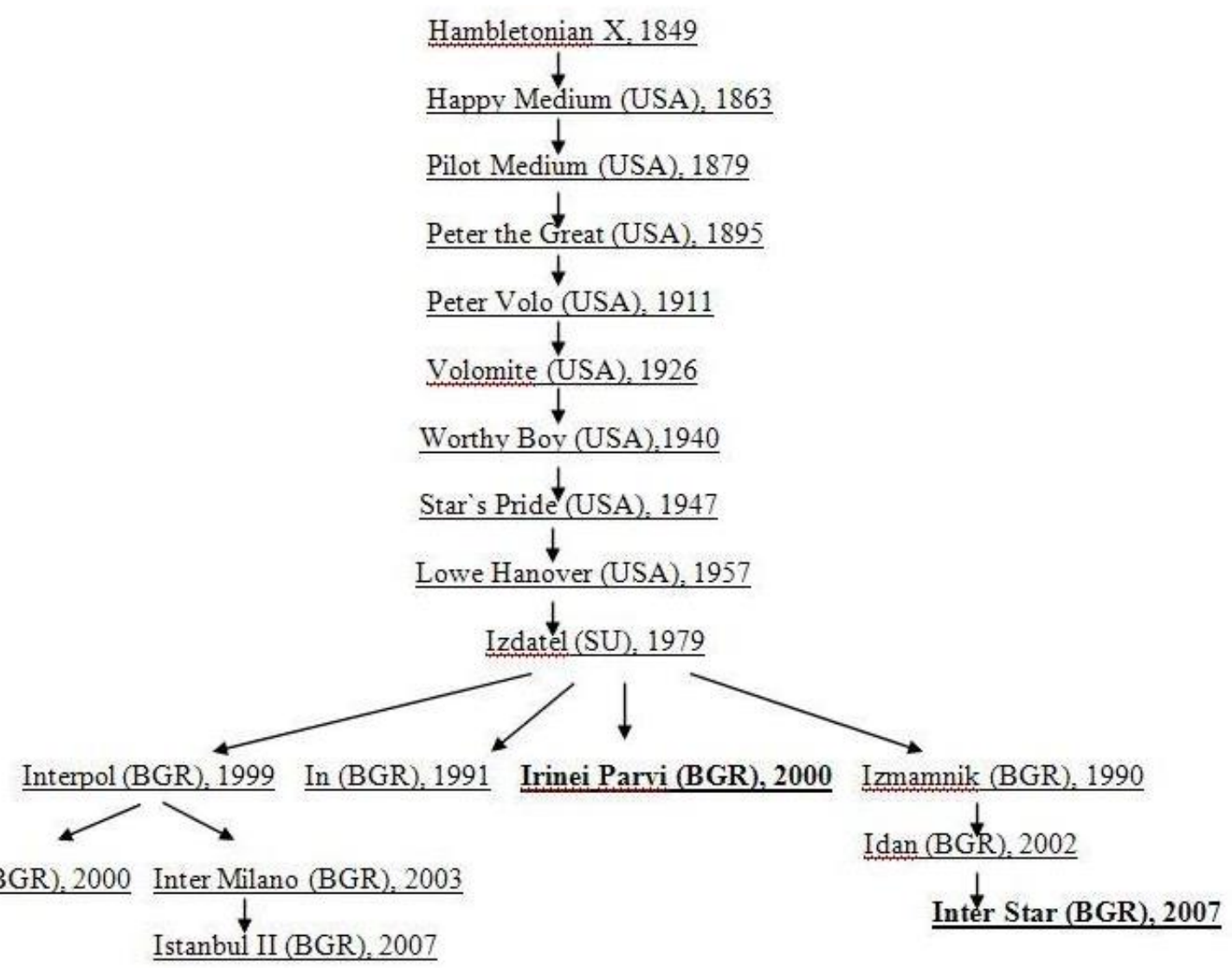

Figure 4. Line of Star`s PrideBranch of Lowe Hanover 
Hambletonian X. 1849

$\frac{\downarrow}{\downarrow}$ Happy Medium (USA), 1863
$\underline{\text { Pilot Medium (USA), } 1879}$

Peter the Great (USA). 1895

Peter Scott (USA), 1909

Scotland (USA), 1925

Spencer Scott (USA), 1937

Rodney (USA), 1944

Speedster(USA), 1954

Speedy Scot (USA), 1960

Centenial Way (USA), 1974

Kirasir (SU), 1988

Komet (BtGR). 1995

Kent (BGR), 2006

Figure 5. Line of ScotlandBranch of Centennial Way

\section{CONCLUSIONS}

1. The development of trotter breeds in Bulgaria is characterized by three distinct periods with different breeding policy. In the first two periods the population was represented by the breeds Orlowski Trotter and Russian Trotter.

2. The large number of stallions belonging to different branches of the main line HambletonianX provides presence and maintenance of broad genetic diversity.

\section{REFERENCE}

1. Burns,E.M., Enns, R.M., Garrick, D.J., The status of equine genetic evaluation. ProceedingsWestern Section Amer. Soc. Anim. Sci., V 55, pp 82-86, 2004.

2. Rozhdestvenskaya, G.A., Line breeding method and its application in studs /Selection and technology of horse raising, selection and methods of animal breeding. Novosibirsk: Nauka, pp 61-68, 1976.

3. Witt, V.O., History of Russian stud development, 1952.

4. Bobinski, K. and Zamoyski, St., Family Tables of Racehorse, 1953.
5. Arnason, T., Genetic selection indices for Swedish Standardbred trotters. Livest.Prod.Sci.,V.72, pp 135-145, 1992.

6. Árnason, T., Genetic evaluation of Swedish standard-bred trotters for racing performance traits and racing status. J. Anim.Breed.Genet.,V.116,pp 387-398, 1999

7. Katona, O. and Distl, O., Sire evaluation in German trotter (Standardbred) population. In: Langlois, B., State of Breeding Evaluation in Trotters. Proceedings of the EAAP Symposium of the Commission of Horse Production, Helsinki, V. 42, pp 37-38, 1988.

8. Kalinkina, G.V., Orlow Trotter /In Collection: Problems and perspectives of Russian studs at the turn of the century., pp 28-30, 2000.

9. Langlois, B., Minkema D., Brims E., Genetic problems in horse breeding // Livestock Product. Sc.,V.10.,pp 69-81, 1983

10. Starodumovym, M.I., Selection programme of improving the Russian Trotter horse breed for the period from 2003 to 2012., Pp 57-58, 2005.

11. Barzev, G. and Yordanov, G., Study on the development of Trotter horse breeds in the studs in the Republic of Bulgaria for the period 1953-2005. Zhivotnovadni nauki, XLIV, V. 5., pp 39-43, 2007. 
